\title{
Pathologically Complete Response after Triple Therapy in Locally Advanced Esophageal Cancer in a Hereditary Hemorrhagic Telangiectasia Patient
}

\author{
Robin Park ${ }^{a}$ Alisdair Philp ${ }^{b}$ Alykhan S. Nagjic Anup Kasi ${ }^{b}$ \\ aDepartment of Medicine, MetroWest Medical Center, Framingham, MA, USA; ${ }^{b}$ Department \\ of Medicine, Division of Medical Oncology, Kansas University Medical Center, Kansas City, \\ KS, USA; 'Department of Cardiovascular and Thoracic Surgery, Kansas University Medical \\ Center, Kansas City, KS, USA
}

\author{
Keywords \\ Locally advanced esophageal cancer · Pathologically complete response · Hereditary \\ hemorrhagic telangiectasia
}

\begin{abstract}
Hereditary hemorrhagic telangiectasia (HHT) is a disorder characterized by vascular manifestations including mucocutaneous and visceral telangiectasias and arteriovenous malformations. Herein we present the case of a relatively young patient with HHT with an incidentally discovered locally advanced esophageal cancer on endoscopic screening and pathologically complete response after neoadjuvant chemoradiation. This case highlights an unusual tumor response to chemoradiation in locally advanced esophageal cancer, and the surveillance care of HHT patients.

(C) 2020 The Author(s).

Published by S. Karger AG, Basel
\end{abstract}

\section{Introduction}

Hereditary hemorrhagic telangiectasia (HHT) is a genetic disorder with an autosomal dominant inheritance and variable penetrance characterized by structural abnormalities of the vasculature, resulting in mucocutaneous telangiectasias and arteriovenous malformations (AVMs) that may involve various organs including the brain, lungs, and the gastrointestinal (GI) tract [1-4]. Prevalence of HHT as suggested by epidemiological studies ranges from 
Park et al.: Pathologically Complete Response of Esophageal Cancer in HHT

1:5,000 to 1:8,000 [5-10]. The Curaçao Criteria have been developed to guide the diagnosis of HHT. The diagnosis is based on the following clinical findings: spontaneous and recurrent epistaxis; multiple mucocutaneous telangiectasia at characteristic sites; visceral manifestations including GI telangiectasia or pulmonary, cerebral, or hepatic AVMs; and a first-degree relative with HHT. Three out of four criteria define "definite," two out of four "suspected," and one out of four "unlikely." Although not necessary, genetic testing may confirm the diagnosis by identifying pathogenic sequence variants in the genes linked to HHT, namely ENG, ACVRL1, or SMAD4 $[10,11]$.

Locally advanced esophageal cancer patients have the option of undergoing triple therapy which includes concurrent neoadjuvant chemoradiation followed by esophageal resection [12]. A minority subset of patients undergoing triple therapy may achieve pathologically complete response (pCR) with studies indicating a range of $19-30 \%$ with a lower rate in adenocarcinoma [13-20]. Such patients enjoy favorable prognoses compared to their non-pCR achieving counterparts in terms of recurrence-free survival and overall survival [14, 21-23]. Therefore, achieving $\mathrm{pCR}$ is an important prognostic measure of locally advanced esophageal cancer patients who have undergone therapy. Herein, we present a patient with underlying HHT who achieves pCR following triple therapy for locally advanced esophageal cancer.

\section{Case Report}

This is a 40-year-old male patient with a recently diagnosed HHT who had undergone screening endoscopy for surveillance of vascular complications. He notes occasional epistaxis and buccal macules but denies nausea, vomiting, dysphagia, and weight loss. His past medical and surgical history is unremarkable. He is a 15-pack-year smoker and drinks $588 \mathrm{~g}$ of alcohol weekly but does not use illicit drugs. Family history is significant for cancer in multiple relatives. His mother suffered from head and neck cancer, his maternal grandmother from colon cancer, his maternal grandfather from prostate cancer, and his paternal grandmother from leukemia. His physical examination is remarkable for buccal telangiectasias and he has a BMI of 32.23. Laboratory studies are remarkable for polycythemia. Upper GI endoscopy shows a friable mucosa with contact bleeding of the esophagus and normal stomach. Several duodenal ectasias are found and treated with plasma coagulation. Capsule endoscopy is done, which is unremarkable. Endoscopic ultrasound shows two periesophageal lymph nodes, 11.6 and 7.2 $\mathrm{mm}$ in diameter (Fig. 1). PET-CT confirmed hypermetabolic primary esophageal tumor but the periesophageal lymph nodes were non-hypermetabolic due to small size. No metastatic lesions are discovered (Fig. 2). Endoscopic biopsy of the ulcerated mucosa of the esophagus confirms moderately differentiated adenocarcinoma in a background of high-grade dysplasia. The patient is diagnosed with stage IIB, cT1bN1 esophageal adenocarcinoma and undergoes neoadjuvant chemoradiation with carboplatin/Taxol then surgical resection with the IVORLewis approach. Postoperative pathology confirms pCR. His 1-month, 1-year and 2-year postoperative surveillance upper GI endoscopies reveal no recurrence.

\section{Discussion}

A potential molecular relationship may exist between a genetic variant underlying a specific subtype of HHT and esophageal cancer pathogenesis. Namely, HHT subtype 1 is associated with pathological variants of $E N G$ which encodes a transformation growth factor beta (TGF- $\beta$ ) superfamily auxiliary receptor [24]. Previous studies have demonstrated downregulation of ENG in esophageal squamous cell cancer cell lines and patient tumor specimens [25]. Furthermore, 
Fig. 1. Endoscopic ultrasound showing 2 periesophageal/perigastric lymph nodes $(11.6 \mathrm{~mm}$, $7.2 \mathrm{~mm})$.

Park et al.: Pathologically Complete Response of Esophageal Cancer in HHT
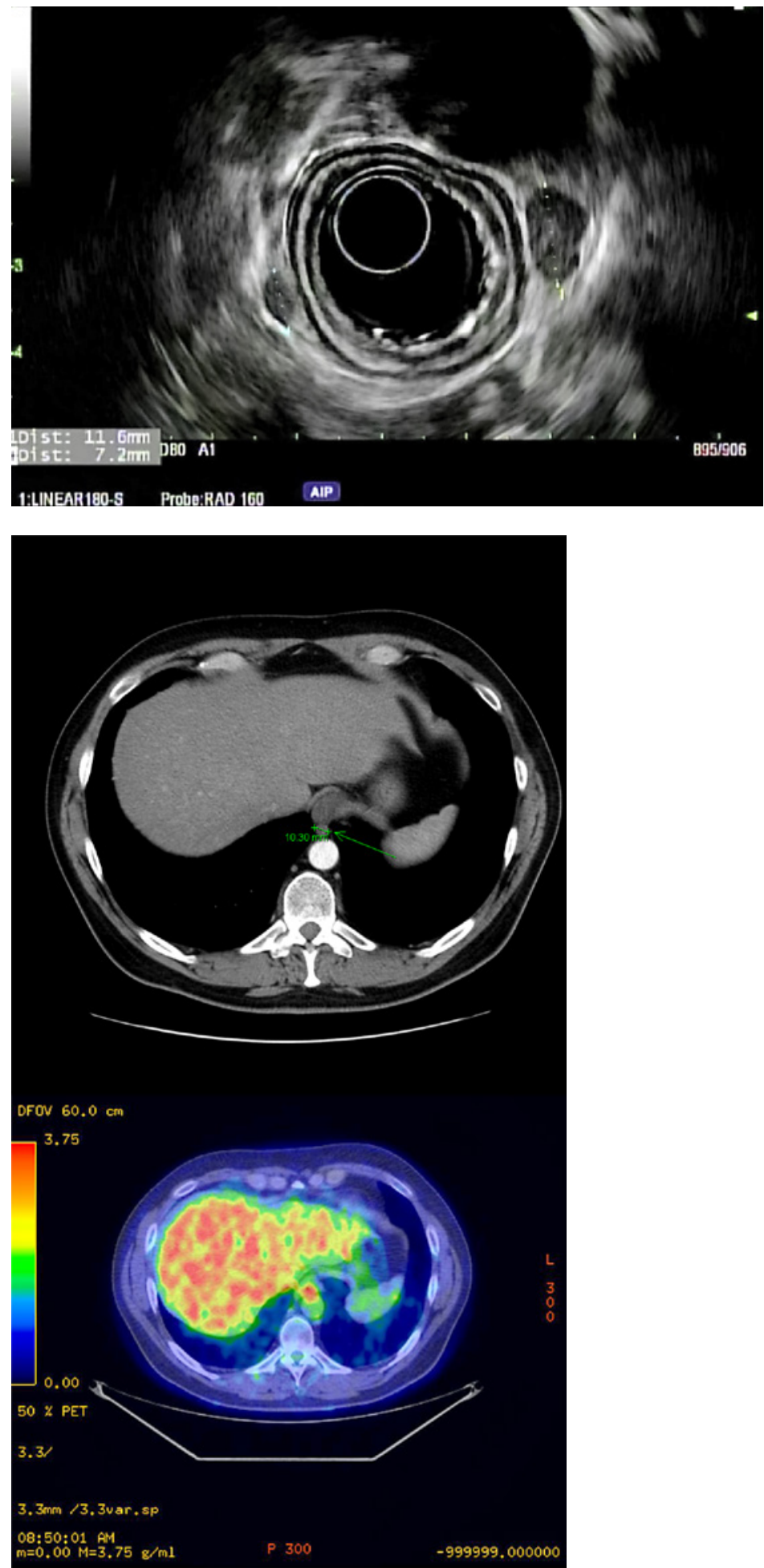

Fig. 2. Staging CT scan of the abdomen showing thickening of the gastroesophageal junction corresponding to the primary lesion. Arrow indicates the neoplastic lesion at the gastroesophageal junction with a diameter of $10.30 \mathrm{~mm}$ (upper panel). Staging PET scan of the abdomen showing hypermetabolism in the corresponding primary lesion. The neoplastic lesion at the gastroesophageal junction demonstrates hypermetabolism (lower panel).

functional in vitro and in vivo studies demonstrate the suppressive effects of $E N G$ on tumor invasion and tumorigenicity [26]. Other studies suggest the involvement of TGF- $\beta$ mediated tumor suppression in the pathogenesis of esophageal adenocarcinoma as well $[27,28]$. Our patient, as part of his previous diagnostic evaluation of HHT, underwent genetic testing, which 
revealed a genetic variant in $E N G$. It is difficult to ascertain if and whether the underlying genetic variant was associated with the onset of esophageal cancer in this relatively young patient, given that he did have risk factors including male sex, obesity, and cigarette smoking [29-32]. However, several epidemiological studies show that HHT1 patients have different specific cancer rates and specific cancer mortality outcomes that differ from the non-HHT1 population $[7,33,34]$. So far, esophageal cancer has not been named as having a different specific cancer rate compared to the healthy population but further studies to evaluate the epidemiological relationship between HHT and esophageal cancer may be warranted.

The management of HHT patients involves timely and judicious screening for clinically significant AVMs. Although international guidelines have been established to facilitate appropriate screening, consensus is still lacking and indications for screening remain unclear in several areas. The major visceral vascular abnormalities that are the subject of screening include cerebral, pulmonary, GI, and hepatic vascular malformations. Evidence for screening for pulmonary AVMs in all patients with possible or confirmed HHT is strong. On the other hand, the evidence is weak for cerebral vascular malformations. Screening for GI AVMs is recommended in patients who are suspected of GI bleeding, namely if anemia appears out of proportion to blood loss by epistaxis. Similarly, screening for liver AVMs is recommended when the liver function test is abnormal or clinical complications arising from liver involvement are suspected [35]. Upon HHT diagnosis, our patient underwent pulmonary screening and GI screening when laboratory studies discovered iron deficiency anemia out of proportion to epistaxis.

As aforementioned, pCR is a positive prognostic indicator and is achieved in approximately $19-30 \%$ of patients who undergo trimodal therapy with neoadjuvant chemoradiation and surgery. Certain clinical factors are associated with lower or higher probability of pCR. Among clinical factors associated with lower pCR are older age $(>60)$, poorly differentiated histology, presence of signet ring cells, higher T stage, and adenocarcinoma subtype [13]. Based on the findings of this study, other than the histological subtype, the patient had none of these oncologic factors, which in retrospect indicated a relatively high pretreatment probability of pCR. Furthermore, the pCR suggests a favorable prognosis for this patient. In fact, the patient is without evidence of recurrence at his 2-year follow-up.

The lessons of this case are the following: (1) screening guidelines and indications for complications in HHT patients are established but many aspects are controversial; (2) certain genetic variants associated with HHT may also be involved in esophageal cancer pathogenesis; and (3) despite its reputation as an aggressive cancer with poor treatment response, locally advanced esophageal cancer can have pCR with surprising frequency.

\section{Conclusion}

This case describes the diagnosis of a locally advanced esophageal cancer in a relatively young patient with a variant gene suspected to be involved in esophageal cancer pathogenesis.

\section{Statement of Ethics}

The authors are accountable for all aspects of the work ensuring that questions related to the accuracy or integrity of any part of the work are appropriately investigated and resolved. Written informed consent was obtained from the patient for the publication of this case report and any accompanying images. A copy of the written consent is available for review by the Editor-in-Chief of this journal. 


\section{Disclosure Statement}

No conflicts of interest to disclose.

\section{Funding Sources}

No funding sources to declare.

\section{Author Contributions}

Robin Park has made substantial contributions to the analysis and interpretation of the work; drafting and revising of the content. Alisdair Philip has made substantial contributions to the analysis and interpretation of data for the work. Alykhan Nagji has made substantial contributions to the conception of the work. Anup Kasi has made substantial contributions to the conception and acquisition of the data for the work; and final revision of the work.

\section{References}

1 Govani FS, Shovlin CL. Hereditary haemorrhagic telangiectasia: a clinical and scientific review. Eur J Hum Genet. 2009;17(7):860-71.

2 Fulbright RK, Chaloupka JC, Putman CM, Sze GK, Merriam MM, Lee GK, et al. MR of hereditary hemorrhagic telangiectasia: prevalence and spectrum of cerebrovascular malformations. AJNR Am J Neuroradiol. 1998; 19(3):477-84.

3 Cottin V, Plauchu H, Bayle JY, Barthelet M, Revel D, Cordier JF. Pulmonary arteriovenous malformations in patients with hereditary hemorrhagic telangiectasia. Am J Respir Crit Care Med. 2004;169(9):994-1000.

4 Brinjikji W, Iyer VN, Yamaki V, Lanzino G, Cloft HJ, Thielen KR, et al. Neurovascular manifestations of hereditary hemorrhagic telangiectasia: a consecutive series of 376 patients during 15 years. AJNR Am J Neuroradiol. 2016;37(8):1479-86.

5 Bideau A, Plauchu H, Brunet G, Robert J. Epidemiological investigation of Rendu-Osler disease in France: its geographical distribution and prevalence. Popul. 1989;44(1):3-22.

6 Dakeishi M, Shioya T, Wada Y, Shindo T, Otaka K, Manabe M, et al. Genetic epidemiology of hereditary hemorrhagic telangiectasia in a local community in the northern part of Japan. Hum Mutat. 2002;19(2):140-8.

7 Kjeldsen AD, Vase P, Green A. Hereditary haemorrhagic telangiectasia: a population-based study of prevalence and mortality in Danish patients. J Intern Med. 1999;245(1):31-9.

8 Guttmacher AE, Marchuk DA, White RI. Hereditary hemorrhagic telangiectasia. N Engl J Med. 1995;333(14): 918-24.

9 Westermann CJ, Rosina AF, De Vries V, de Coteau PA. The prevalence and manifestations of hereditary hemorrhagic telangiectasia in the Afro-Caribbean population of The Netherlands Antilles: a family screening. Am J Med Genet A. 2003;116A(4):324-8.

10 Shovlin CL, Buscarini E, Kjeldsen AD, Mager HJ, Sabba C, Droege F, et al. European reference network for rare vascular diseases (VASCERN) outcome measures for hereditary haemorrhagic telangiectasia (HHT). Orphanet J Rare Dis. 2018;13(1):136.

11 Shovlin CL, Guttmacher AE, Buscarini E, Faughnan ME, Hyland RH, Westermann CJ, et al. Diagnostic criteria for hereditary hemorrhagic telangiectasia (Rendu-Osler-Weber syndrome). Am J Med Genet. 2000;91(1): 66-7.

12 Chan KKW, Saluja R, Delos Santos K, Lien K, Shah K, Cramarossa G, et al. Neoadjuvant treatments for locally advanced, resectable esophageal cancer: a network meta-analysis. Int J Cancer. 2018;143(2):430-7.

13 Blum Murphy M, Xiao L, Patel VR, Maru DM, Correa AM, G Amlashi F, et al. Pathological complete response in patients with esophageal cancer after the trimodality approach: the association with baseline variables and survival-The University of Texas MD Anderson Cancer Center experience. Cancer. 2017;123(21):4106-13.

14 Meguid RA, Hooker CM, Taylor JT, Kleinberg LR, Cattaneo SM, Sussman MS, et al. Recurrence after neoadjuvant chemoradiation and surgery for esophageal cancer: does the pattern of recurrence differ for patients with complete response and those with partial or no response? J Thorac Cardiovasc Surg. 2009;138(6):1309-17.

15 van Hagen P, Wijnhoven BP, Nafteux P, Moons J, Haustermans K, De Hertogh G, et al. Recurrence pattern in patients with a pathologically complete response after neoadjuvant chemoradiotherapy and surgery for oesophageal cancer. Br J Surg. 2013;100(2):267-73. 
Park et al.: Pathologically Complete Response of Esophageal Cancer in HHT

16 Smit JK, Güler S, Beukema JC, Mul VE, Burgerhof JG, Hospers GA, et al. Different recurrence pattern after neoadjuvant chemoradiotherapy compared to surgery alone in esophageal cancer patients. Ann Surg Oncol. 2013; 20(12):4008-15.

17 Luc G, Gronnier C, Lebreton G, Brigand C, Mabrut JY, Bail JP, et al. Predictive factors of recurrence in patients with pathological complete response after esophagectomy following neoadjuvant chemoradiotherapy for esophageal cancer: a multicenter study. Ann Surg Oncol. 2015;22 Suppl 3:S1357-1364.

18 Kim MK, Cho KJ, Park SI, Kim YH, Kim JH, Song HY, et al. Initial stage affects survival even after complete pathologic remission is achieved in locally advanced esophageal cancer: analysis of 70 patients with pathologic major response after preoperative chemoradiotherapy. Int J Radiat Oncol Biol Phys. 2009;75(1):115-21.

19 Chao YK, Chen HS, Wang BY, Hsu PK, Liu CC, Wu SC. Factors associated with survival in patients with oesophageal cancer who achieve pathological complete response after chemoradiotherapy: a nationwide populationbased study. Eur J Cardiothorac Surg. 2017;51(1):155-9.

20 Huang RW, Chao YK, Wen YW, Chang HK, Tseng CK, Chan SC, et al. Predictors of pathological complete response to neoadjuvant chemoradiotherapy for esophageal squamous cell carcinoma. World J Surg Oncol. 2014;12: 170.

21 Vallböhmer D, Hölscher AH, DeMeester S, DeMeester T, Salo J, Peters J, et al. A multicenter study of survival after neoadjuvant radiotherapy/chemotherapy and esophagectomy for ypT0N0M0R0 esophageal cancer. Ann Surg. 2010;252(5):744-9.

22 Abate E, DeMeester SR, Zehetner J, Oezcelik A, Ayazi S, Costales J, et al. Recurrence after esophagectomy for adenocarcinoma: defining optimal follow-up intervals and testing. J Am Coll Surg. 2010;210(4):428-35.

23 Taketa T, Sudo K, Correa AM, Wadhwa R, Shiozaki H, Elimova E, et al. Post-chemoradiation surgical pathology stage can customize the surveillance strategy in patients with esophageal adenocarcinoma. J Natl Compr Canc Netw. 2014;12(8):1139-44.

24 McAllister KA, Grogg KM, Johnson DW, Gallione CJ, Baldwin MA, Jackson CE, et al. Endoglin, a TGF-beta binding protein of endothelial cells, is the gene for hereditary haemorrhagic telangiectasia type 1. Nat Genet. 1994; 8(4):345-51.

25 Wong VC, Chan PL, Bernabeu C, Law S, Wang LD, Li JL, et al. Identification of an invasion and tumor-suppressing gene, Endoglin (ENG), silenced by both epigenetic inactivation and allelic loss in esophageal squamous cell carcinoma. Int J Cancer. 2008;123(12):2816-23.

26 Lin EW, Karakasheva TA, Hicks PD, Bass AJ, Rustgi AK. The tumor microenvironment in esophageal cancer. Oncogene. 2016;35(41):5337-49.

27 Lee SW, Lien HC, Lin CC, Wen MC, Chang CS. Low expression of transforming growth factor $\beta$ in the epithelium of Barrett's esophagus. Gastroenterol Res. 2018;11(3):189-94.

28 Mendelson J, Song S, Li Y, Maru DM, Mishra B, Davila M, et al. Dysfunctional transforming growth factor- $\beta$ signaling with constitutively active Notch signaling in Barrett's esophageal adenocarcinoma. Cancer. 2011; 117(16):3691-702.

29 Mathieu LN, Kanarek NF, Tsai HL, Rudin CM, Brock MV. Age and sex differences in the incidence of esophageal adenocarcinoma: results from the Surveillance, Epidemiology, and End Results (SEER) Registry (1973-2008). Dis Esophagus. 2014;27(8):757-63.

30 MacDonald WC, MacDonald JB. Adenocarcinoma of the esophagus and/or gastric cardia. Cancer. 1987;60(5): 1094-8.

31 Lauby-Secretan B, Scoccianti C, Loomis D, Grosse Y, Bianchini F, Straif K, et al. Body fatness and cancer-viewpoint of the IARC working group. N Engl J Med. 2016;375(8):794-8.

32 Cook MB, Kamangar F, Whiteman DC, Freedman ND, Gammon MD, Bernstein L, et al. Cigarette smoking and adenocarcinomas of the esophagus and esophagogastric junction: a pooled analysis from the international BEACON consortium. J Natl Cancer Inst. 2010;102(17):1344-53.

33 Kjeldsen A, Aagaard KS, Tørring PM, Möller S, Green A. 20-year follow-up study of Danish HHT patientssurvival and causes of death. Orphanet J Rare Dis. 2016;11(1):157.

34 Hosman AE, Devlin HL, Silva BM, Shovlin CL. Specific cancer rates may differ in patients with hereditary haemorrhagic telangiectasia compared to controls. Orphanet J Rare Dis. 2013;8:195.

35 Faughnan ME, Palda VA, Garcia-Tsao G, Geisthoff UW, McDonald J, Proctor DD, et al. International guidelines for the diagnosis and management of hereditary haemorrhagic telangiectasia. J Med Genet. 2011;48(2):73-87. 